\title{
OPMERKINGEN BIJ HET DISCUSSIERAPPORT 8 VAN DE WERKGROEP HERZIENING BEROEPSREGELS OVERHEIDSACCOUNTANTS
}

\author{
door S. Deijs
}

\section{Inleiding}

Wat is de oorsprong van de tegenstelling tussen overheidsaccountants en openbare accountants? Dit is ontegenzeggelijk een vraag waarmee de commissie geconfronteerd is, hoewel dit in het rapport niet zo expliciet naar voren komt. We bevinden ons hier op een terrein dat dikwijls gekenmerkt wordt door oppervlak kige en eenzijdige uitspraken en constateringen zonder dat sprake is van een diepgaande analyse die op de inhoud van de problematiek is gericht. Dit vloeit naar mijn mening voort uit enerzijds de aard van de materie, welke de achtergrond vormt en anderzijds de benadering uitsluitend vanuit het accountantsberoep. Dit is op zichzelf niet zo verwonderlijk, maar toch dient bedacht te worden dat er invloeden en aspecten kunnen zijn, die het wezenlijke van de vragen raken en die derhalve niet genegeerd mogen worden.

De kwalitatieve begrippen verantwoordelijkheid en afhankelijkheid vormen de basis van het rapport zonder dat getracht is hiervan omschrijvingen te geven. Dit zal ook niet zo eenvoudig zijn daar in een vakuitoefening het gaat om de kwan. tificering, men zal er iets mee moeten kunnen doen. En de relatie tussen een kwalitatief begrip en de concretisering ervan is uiteindelijk een kwestie van afspraak. Deze manifesteert zich in een regel tot stand gekomen op grond van macht en moraal. Nu wijzigen macht en moraal voortdurend, zodat oplossingen van het verleden nu niet meer gelden en vroegere uitgangspunten niet voldoende zijn om de hedendaagse problemen te analyseren. Dit is ook vaak de oorzaak van tegen. gestelde opvattingen tussen de belanghebbende accountantsgroepen. Aan ieder van de standpunten kan meestal een zeker waarheidsgehalte niet worden ontzegd. Maar een visie kan te partieel zijn, zodat iedere groep meent het "gelijk" aan zijn kant te hebben.

Het bovenstaande moge de verklaring vormen voor de opzet van dit artikel. Nadat op verantwoordelijkheid en afhankelijkheid in meer algemene zin is inge. gaan worden enige beschouwingen gewijd aan de concrete voorstellen van de commissie met als achtergrond de voorafgegane analyse.

\section{Verantwoordelijkheid}

\section{Begrip}

Bij verantwoordelijkheid gaat het om een kenmerk van de relatie van een persoon of groep tot de omgeving (mensen en dingen). Dikwijls wordt de verant. woordelijkheid in relatie gezien met delegatie. Delegatie gaat spelen daar waar het overdragen van werkzaamheden gepaard gaat met of gevolgd wordt door het overdragen van bevoegdheden tot handelen. Dit handelen dient dus gepaard te gaan met macht. Door deze bevoegdheden tot handelen ontvangt de gedelegeerde een bepaalde bewegingsvrijheid, die een eigen verantwoordelijkheid doet ont. 
staan. Dit is op zichzelf vanzelfsprekend omdat ieder die een taak moet vervullen daarvoor verantwoordelijk is en daarover verantwoording schuldig is. Die verant. woordelijkheid zou niet kunnen worden gedragen indien niet overeenkomstige bevoegdheden waren gedelegeerd. Wanneer dusdanige uitvoeringsregelen zijn gegeven dat de gedelegeerde geen vrijheid van handelen heeft spreken wij niet van delegatie maar van overdragen van werk. In feite zijn dan geen bevoegdhe den overgedragen.

Deze onderscheiding tussen overdracht van werk en delegatie heeft betekenis voor de inhoud van de verantwoordelijkheid, d.w.z. voor de gevolgen van eigen handelen. De gedelegeerde is verantwoordelijk voor de uitvoering van de taak en van de wijze waarop hij deze heeft uitgevoerd. Immers hij had bewegingsvrij. heid en zal dus uit alternatieve mogelijkheden een keus moeten doen, zij het dat de vrijheid van keus bepaald is binnen algemene lijnen, die de delegant heeft vast. gesteld. Bij het overdragen van werkzaamheden heeft de uitvoerder slechts een verantwoordelijkheid voor de uitvoering overeenkomstig de aangegeven instructies.

Het gaat bij de taken en bevoegdheden niet altijd om door anderen opgelegde taken. Er kan ook sprake zijn van zichzelf opgelegde taken. Men voelt zich dan verantwoordelijk.

Nu behoudt de delegant (wanneer we ons bepalen tot de bedrijfshuishouding) de volle verantwoordelijkheid ook nà delegatie. Dit vloeit voort uit het zelfstandige karakter van elke bedrijfshuishouding als geheel en de onzelfstandigheid van de organen in de bedrijfshuishouding. De organische gebondenheid van alle in de organisatie structuur aanwezige organen en eenheden van verantwoordelijk. heid is de diepere oorzaak van de omstandigheid dat de verantwoordelijkheid voor de taak, ingeval van delegatie, bij de taakoverdrager blijft berusten, ofschoon niettemin de verantwoordelijkheid aan de taak inhaerent is. Bij de delegant be. rust de integrale verantwoordelijkheid, terwijl de gedelegeerde een partiële verantwoordelijkheid heeft. Deze onderscheiding in integrale en partiële verant woordelijkheid heeft slechts betekenis voor de structuur der verantwoordelijk. heid.

Hoewel dus de delegant de volle verantwoordelijkheid behoudt, verandert er toch veel waar de verantwoordelijkheid niet buiten staat. Men zou kunnen stellen dat de inhoud van de verantwoordelijkheid is gewijzigd. Dit vloeit ook recht. streeks voort uit de verbondenheid van taak en verantwoordelijkheid. De verant woordelijkheid van de delegant heeft betrekking op de volgende drie punten:

1. wat hij heeft gedelegeerd

2. aan wie is gedelegeerd

3. hoe de delegatie is geregeld.

Over elk van deze drie punten worden enige opmerkingen gemaakt. Ten aanzien van de taak die is gedelegeerd dient de delegant na te gaan of deze delegatie in overeenstemming is met de beginselen van de organisatie structuur. Te wijzen valt op het beginsel van centralisatie en decentralisatie.

Bij de keus van de gedelegeerde dient nagegaan te worden of deze de taak kan uitvoeren. Men kan iemand slechts zoveel delegeren als de taakuitvoerder nog kan overzien. Er dient evenwicht te bestaan tussen taak en capaciteiten.

Ten aanzien van de werkwijze van de delegant wordt opgemerkt dat de dele. gant de gedelegeerde voortdurend op de hoogte moet stellen van de doelstellin 
gen van het algemeen beleid en de achtergronden daarvan, maar ook zal hij er voor moeten zorgen dat hij voortdurend geïnformeerd blijft omtrent de wijze waarop de gedelegeerde van zijn bevoegdheden heeft gebruik gemaakt.

De gedelegeerde zal de delegant op overzichtelijke wijze een inzicht moeten geven omtrent de wijze waarop hij zijn taak vervult en hij zal de nodige informatie en adviezen moeten geven, die van belang zijn voor de beleidsbepaling door de delegant.

\section{Geregelde en niet-geregelde verantwoordelijkheid}

Bij de verantwoordelijkheid wordt wel onderscheid gemaakt in geregelde en niet. geregelde verantwoordelijkheid. Vooral bij hogere functies komt de niet-geregel. de verantwoordelijkheid voor. Men is dan zeer sterk aangewezen op eigen inzich ten en uitgangspunten. Daar deze dikwijls van persoon tot persoon verschillen ontstaan in organisaties spanningsvelden, die zelfs tot ontwrichting van de organisatie kunnen leiden. Er kan verwarring optreden. De introductie van nieuwe denkbeelden door democratisch denkenden wekt soms angst bij de autocratisch ingestelde dogmatici.

\section{Persoonlijke en institutionele verantwoordelijkheid}

De verantwoordelijkheid speelt niet alleen bij personen. Ook gaat het om groepen van belanghebbenden. Terwijl bij de eerste het vooral gaat om de persoon lijke verantwoordelijkheid is bij de tweede sprake van institutionele verantwoor. delijkheid. Ook tussen deze twee bestaat een spanning. De persoonlijke verant woordelijkheid betreft in hoofdzaak de eigen belangen. Bij de institutionele ver antwoordelijkheid is vooral essentieel het belang van anderen, die buiten het ge zichtsveld kunnen blijven van hen die een persoonlijke verantwoordelijkheid dra gen.

\section{Relatie verantwoordelijkheid - uitkomst}

Een bijzonder aspect bij de verantwoordelijkheid is de relatie (en nu denk ik concreet aan accountants) met de verklaring als zijnde de uitkomst van de verrichte arbeid. Dit houdt in een betrokkenheid met die uitkomst. De causale relatie tussen de arbeid en de uitkomst betekent voor de accountant veel. Hierbij gaat het om de „wijze van zijn in de wereld”. Deze is gekenmerkt door een houding of instel ling, welke naar buiten zichtbaar is in een bepaald gedrag. Bij de opleidingsdoelen worden wel verschillende niveaus in dit opzicht onderscheiden, die van lagere naar hogere niveaus luiden: gevormd, aangepast, ontvankelijk, zelfstandig, stre vend, zich-ontwikkelend en scheppend. Deze opsomming alleen al illustreert de rijke variatie in houdingselementen.

\section{Afhankelijkheid}

\section{Begrip}

Evenals verantwoordelijkheid is afhankelijkheid een kenmerk van een relatie van een persoon of groep tot de omgeving (mensen en dingen). Bij afhankelijkheid is de mens niet vrij in zijn handelen. Dit kan een gevolg zijn van machtsverhou. dingen of van rechtsregels. Eveneens bestaat er een relatie van macht en recht. Volgens bepaalde theorieën berust het recht op macht. Anderzijds is macht voor een deel vervangen door recht. 
Het is noodzakeljk er nog een ander aspect bij te halen. Namelijk de moraal. We denken dan aan de gedragsregels vanuit een innerlijk gezag, waarbij de samenleving als geheel is betrokken. Het begrip maatschappelijk verkeer kan hier ten tonele gevoerd worden. Als we spreken van de wil van het maatschappelijk verkeer wordt hiermee bedoeld dat het gaat om de publieke opinie als representant van de samenleving. Deze opinie vormt een macht, die de inhoud van de mo. raal bepaalt. Men denkt er dan zus of zo over; het is een gewoonte of zede van de gemeenschap.

Er bestaat een verband tussen macht en moraal als elkaar vervangend. Als er een goede moraal is zal er minder behoefte zijn door rechtsregels dwingende maatregelen te nemen.

Hoe een moraal ontstaat is een vraagstuk waar verschillende theorieën over bestaan. Dat wordt hier buiten beschouwing gelaten. Niettemin kan niemand het bestaan van een moraal ontkennen. Die is er. We behoeven maar te denken aan arbeidsmoraal, sexmoraal, milieu-moraal enz. Het gemeenschappelijke bij een moraal is dat een eenmaal ontstane moraal niet zo eenvoudig verandert. Dit is ook logisch als we denken aan de functies van de moraal. Als zodanig worden in de literatuur wel genoemd:

a. het regelen van het gedrag

b. continuiteit van bestaande verhoudingen

c. overleven van groepen en samenlevingen

d. het verlenen van identiteit

$e$. het ontstaan van rechtsregels.

Zoals reeds werd opgemerkt heeft moraal een consistent karakter. Soms is een bepaald feit of gebeurtenis echter in staat de oude moraal geleidelijk te veran deren. Dan wordt pas ervaren dat bij een andere moraal de wereld ook nog draait en dat er niets verloren is door de moraal aan te passen. Integendeel dikwijls ont. staat dan de openlijke erkenning dat het oude uitgangspunt een dogma was met een betrekkelijke waarde. Iedereen zal erkennen dat de geschiedenis vol is met nederlagen van dogma's.

Wanneer door wijzigende moraal er een afwijking ontstaat met bestaande rechtsregels spreekt men aanvankelijk van een slechte moraal. Er wordt dan getracht door macht de naleving van rechtsregels af te dwingen. Iedereen kan wel voorbeelden bedenken. $\mathrm{Na}$ enige tijd wordt dan meestal de rechtsregel aange. past.

\section{Functionele onafhankelijkheid}

In ons beroep heeft de onafhankelijkheid in functie vanaf het begin een belang. rijke betekenis gehad. Daarop behoeft nauwelijks te worden ingegaan. Het uiteindelijke motief was dat het maatschappelijk verkeer die nu eenmaal als eis stelde. Het was de heersende moraal.

In de literatuur is er wel op gewezen dat ook andere factoren invloed uitoe fenen op de onafhankelijkheid, met name geldelijk belang en karakter. Dit aspect is wel afgedaan met de opmerking dat deze factoren liggen buiten het vraagstuk van de functie.

Sommigen hebben mogelijk wel eens het onbevredigend gevonden dat de in tegratie van de tegenstelling (mentaliteit - functie) niet tot stand kwam. De hierboven gegeven analyses hebben duidelijk gemaakt dat er een relatie is met de 
moraal. De wil van het maatschappelijk verkeer steunt nu eenmaal hier op. Iedere samenleving heeft de moraal die zij nodig heeft. Ze wijkt in het westen af van die in het oosten. Als zodanig is er een invloed op het ontstaan van de functie van de accountant.

In het accountantsberoep is niet expliciet getracht de relatie met de moraal te leggen. Stellen wij dus enerzijds vast dat er een relatie is van de functie en de moraal, anderzijds wordt die relatie betwist. Waar zit dat nu in? Naar onze mening gaat het om de moraal van de samenleving of het maatschappelijk verkeer en niet om de mentaliteit van een individu. Iedereen weet wel dat dikwijls een groep of collectiviteit aangeduid wordt waarbij er van uitgegaan wordt dat de individuen allemaal de kenmerken van de groep vertonen. Zo spreekt men van "de” Duitser, „de" ambtenaar, „de” public etc. Het doet er ook niet zoveel toe als een individu afwijkt van de heersende moraal zolang er maar geen situaties ontstaan die de samenleving aanleiding geven te protesteren tegen een structuur die in gaat tegen de moraal.

\section{Enige opmerkingen over het discussierapport}

\section{Taakopdracht}

De werkgroep is verzocht te onderzoeken welke maatregelen mogelijk zijn om de onafhankelijkheid naar wezen en schijn van de accountant in dienst van de overheid die optreedt als openbaar accountant te vergroten en te onderzoeken of daarmee deze onafhankelijkheid voldoende wordt gewaarborgd.

In het rapport is het begrip onafhankelijkheid naar wezen en schijn niet toegelicht of door voorbeelden gestaafd. Voor sommigen zal het misschien een vraag zijn wat verstaan wordt onder de onafhankelijkheid naar wezen. Immers alleen wanneer hieromtrent duidelijkheid bestaat kan nagegaan worden of de door de commissie gedane aanbevelingen wel relevant zijn. De onafhankelijkheid in wezen betreft de moraal. Immers dit is het essentiële. „The independence in mental attitude", geldt hier. De ,independence in appearance” is in het rapport aangeduid met de onafhankelijkheid in schijn. Hebben de aspecten „in wezen” en ,in schijn" een relatie tot elkaar? Betekent een onafhankelijkheid in schijn ook een onafhankelijkheid naar wezen? Of moeten wij zeggen „schijn bedriegt”?

In het vervolg van dit artikel zal nader ingegaan worden op de inhoud van enige aanbevelingen. Hier wordt reeds aangeduid dat het scheppen van onafhankelijkheid door regelingen of door machtsverhoudingen niet betekent dat deze regels ook altijd zullen worden nageleefd. Immers tussen macht en moraal bestaat soms een discrepantie. Door die discrepantie onttrekt men zich met een grote mate van vanzelfsprekendheid aan de gevolgen van eigen handelen. Dit kan het gevolg zijn van de omstandigheid dat de macht onvoldoende door bijbehorende moraal wordt gedekt.

Zou de onafhankelijkheid in wezen vergroot kunnen worden door beïnvloe. ding van de moraal via organisatorische maatregelen? Hier wordt gedacht aan de organisatie structuur in democratische zin. De ambtelijke organisaties worden echter dikwijls gekenmerkt door een autocratische structuur. Het verlenen van meer bevoegdheid is voor de moraal en de onafhankelijkheid van grote beteke. nis. Zolang de autocratische structuren binnen de accountantsdiensten worden 
gehandhaafd zijn maatregelen op het terrein van de onafhankelijkheid in schijn voor de in dienstverband werkende registeraccountant waarschijnlijk van geringe of geen betekenis.

Terecht worden door de commissie bij de maatregelen die mogelijk zijn drieërlei aspecten onderscheiden:

a. het opnemen c.q. wijzigen van specifieke bepalingen voor overheidsaccoun tants in de Gedrags- en Beroepsregels Registeraccountants;

$b$. wijziging van wettelijke en ambtelijke voorschriften met betrekking tot het fungeren van overheidsaccountants;

c. wijziging van bestaande structuren waarin overheidsaccountants hun werkzaamheden verrichten.

Bij de specifieke vragen waaraan de werkgroep aandacht zal dienen te geven is o.a. de vraag opgenomen: „Welke betekenis kan het zijn van ambtenaar hebben voor de onafhankelijkheid (naar wezen en schijn) van de overheidsaccountant?" Naar mijn mening is dit de kernvraag welke direct verband houdt met de struc. turen van de accountantsdiensten.

Uiteraard richt het rapport het zoeklicht op de overheidsaccountant die optreedt als openbaar accountant. Dit was nu eenmaal de opdracht van de commis. sie. Uit het rapport blijft de indruk echter achter dat het toch zo nodig is regels te maken die de onafhankelijkheid moeten versterken. De maatregelen moeten hem als het ware helpen. Een mogelijke frustratie zou het gevolg kunnen zijn. Toch dient bedacht te worden dat hetgeen in de inleiding van dit artikel is uiteengezet onverkort geldt voor de zelfstandig optredende openbare accountant. $\mathrm{Er}$ is misschien een aspect waarin de overheidsaccountant bij een goede organisatie voordelen heeft boven de zelfstandige accountant. Ik denk aan de afstand in morele zin. De vertrouwensrelatie tussen de cliënt en de accountant is mogelijk sterker bij de particuliere accountant. Ze kan zelfs zo sterk worden dat het moreel moeilijk wordt iets „ongunstigs” te zeggen. Slechts een collectief optreden bij het accountantskantoor kan hier uitkomst bieden. De afstand wordt dan vergroot. Het is zonder meer duidelijk dat bij de overheidsaccountants een solitair optreden dezelfde bezwaren heeft als gememoreerd bij de particuliere accountant. Ook hier zal een gedeelde verantwoordelijkheid bij de overheidsdienst slechts uitkomst kunnen bieden. De structuur van de accountantsdienst zal dan hierin moe. ten voorzien.

2. Maatregelen om de mate van onafhankelijkheid van de ambtenaar-accountant op het maximale niveau te brengen dat in de gegeven omstandigheden bereikbaar is

Hoofdstuk 7 van het rapport handelt over de controleur van de voor bekendma. king buiten de overheid bestemde periodieke beheersverantwoording van een overheidsorgaan. Onder 7.6 wordt duidelijk gezegd dat de ambtenaar-accountant feitelijk nimmer onafhankelijk is. Men kan niet verder komen dan waarborgen te bedenken voor een zo groot mogelijke mate van onafhankelijkheid. Deze waar. borgen vinden we in bijlage 4 als een „Proeve van een Algemene Maatregel van Bestuur waarin waarborgen worden omschreven voor de onafhankelijkheid van de ambtenaar-accountant die belast is met het geven van een voor openbaarmaking bestemde verklaring".

Het gaat hier met name nog om het uitgangspunt van de functionele onafhankelijkheid. Zoals hiervoor in hoofdstuk III sub 2 reeds werd uiteengezet is de eis 
van functionele onafhankelijkheid gebaseerd op de moraal van de samenleving. Ervan uitgaande dat de moraal deze eis stelt kan echter betwijfeld worden of de voorgestelde maatregelen de onafhankelijkheid in wezen vergroten. Deze laatste betreft namelijk, zoals hiervoor is toegelicht, de mentaliteit van het individu. De regeling heeft dan ook alleen maar betekenis voor de onafhankelijkheid in schijn. De betekenis hiervan kan hoogstens zijn dat de samenleving (het maatschappelijk verkeer) geen verwijten kan maken op grond van vermeende onjuistheden. In deze zin heeft de commissie oog gehad voor de wenselijkheid van het voorkomen van iedere schijn dat de uitkomsten van de accountant door de verhoudingen zouden zijn beïnvloed.

Ten aanzien van 7.15 zij het volgende opgemerkt. De werkgroep betuigt in stemming met de gedachten blijkende uit het concept voor „Wet reorganisatie binnenlands bestuur", waarin wijzigingen zijn opgenomen van de Provinciewet en de Gemeentewet. Ten aanzien van de deskundigen belast met de controle wordt nl. in het concept gesteld dat zij:

a. wat betreft de provincies, niet mogen zijn ambtebaar door of vanwege het provinciaal bestuur aangesteld of daaraan ondergeschikt;

b. wat betreft de gemeenten niet mogen zijn lid van het gemeentebestuur; ambtenaar door of vanwege het gemeentebestuur aangesteld of daaraan onder geschikt; of op arbeidsovereenkomst naar burgerlijk recht in dienst van de ge. meente werkzaam zijn.

Waar ik ook vraagtekens bij zet is de clausule in het rapport onder 7.15 dat deze gedachten er toe kunnen leiden dat de onafhankelijkheid in wezen van de met de controle van provincie of gemeente belaste accountant wordt vergroot.

De Proeve van een Algemene Maatregel van Bestuur waarin waarborgen wor den omschreven voor de onafhankelijkheid van de ambtenaar accountant die be last is met het geven van een voor openbaarmaking bestemde verklaring (bijlage 4) bevat evenmin enige bepaling, die de onafhankelijkheid in wezen zou kunnen beinvloeden.

3. Proeve van een modelverordening voor een Gemeentelijke Accountantsdienst en Proeve van een statuut voor de regeling van de onafhankelijkheid van het Accountantskantoor van de Vereniging van Nederlandse Gemeenten Centraal Bureau voor Verificatie en Financiele Adviezen (V.N.G.)

Deze stukken zijn opgenomen op bijlage 5 en bijlage 7 van het rapport. Onder. delen van artikelen van beide proeven worden hier om de lezing van dit artikel te vergemakkelijken weergegeven.

GEMEENTE: art. 2 lid 1. Aan het hoofd van de dienst staat de directeur, aan wie het aan de dienst verbonden personeel ondergeschikt is.

art. 3 lid 1. De directeur en het personeel zijn in de uitoefening van hun werk zaamheden onafhankelijk van hun opdrachtgever en van degene omtrent wiens aangelegenheden verklaringen worden afgegeven, alsmede van degene die be langen heeft bij of afhankelijk is van een van hen, of van beiden.

art. 3 lid 2. Indien de directeur van oordeel is dat de onafhankelijkheid als in lid 1 bedoeld wordt aangetast, dreigt te worden aangetast of in onvoldoende mate gewaarborgd is, wendt hij zich tot de Gemeenteraad met het verzoek de maatregelen te treffen die nodig zijn om de onafhankelijkheid te waarborgen. Al vorens de Gemeenteraad een zodanig besluit neemt, wint hij terzake advies in 
bij de Orde Nederlands Instituut van Registeraccountants.

art. 3 lid 3. De directeur brengt een doeltreffende vaktechnische organisatie tot stand, zodat de uit artikel 2, lid 1 voortvloeiende verantwoordelijkheid door de directeur kan worden gedragen.

VERENIGING NED. GEMEENTEN: art. 2 lid 1. De leiding van het Accountantskantoor en de eindverantwoordelijkheid voor een juiste beroepsuitoefening berusten bij een directie aan wie het personeel hiërarchisch ondergeschikt is.

art. 2 lid 2. De directie beslist over aanvaarding en opzegging van opdrachten door het Accountantskantoor.

art. 3 lid 2. De directie brengt een doeltreffende vaktechnische organisatie tot stand zodat de uit artikel 2 voortvloeiende verantwoordelijkheid door de directieleden kan worden gedragen.

art. 5. De eindverantwoordelijkheid van de directie voor de juiste beroepsuitoefening tast de op de Wet op de Registeraccountants steunende en in de GBR bedoelde eigen vaktechnische verantwoordelijkheid voor de overige bij het Ac. countantskantoor werkzame registeraccountants niet aan.

Achtereenvolgens worden enige opmerkingen gemaakt over:

a. de verantwoordelijkheid

b. de onafhankelijkheid.

\section{ad a. DE VERANTWOORDELUKHEID}

Een wezenlijk punt in beide proeven is de als een gebod uitgesproken dreiging van ondergeschiktheid bij de gemeente en, om het aspect nog iets sterker te ac. centueren, hiërarchische ondergeschiktheid bij de V.N.G.

In verband met de verantwoordelijkheid lijkt het zinvol enige punten aan te halen uit het boek „Limperg/Groeneveld: Leer van de accountantscontrole”. In het bijzonder de pagina's 292-296 handelend over de arbeidsverdeling en verantwoordelijkheid. De belangstellende lezer zij aanbevolen van het geheel kennis te nemen. Hier worden enige alinea's er uit gelicht, die voor het verdere betoog van belang zijn.

\section{„DE VERANTWOORDELIJKHEID VAN DE MEDEWERKERS}

Bestond diens eigen verantwoordelijkheid niet, dan was de zaak eenvoudig. Dan stond de zaak principieel niet anders bij de medewerker dan bij de assistent, maar dan zou ook van delegatie van verantwoordelijkheid geen sprake kunnen zijn. Dan zou ook de accountant-medewerker principieel niet meer kunnen zijn dan een eerste assistent.

De overdracht van de functie gaat dus gepaard met delegatie van de verant. woordelijkheid; en die kán ook plaatsvinden, indien er een bevoegde medewer. ker is.

Er rijst echter een moeilijkheid, indien de accountant-werkgever de medewer. ker niet de volle vrijheid laat. Daarbij is het paradoxale, dat de medewerker in waarheid in een goede organisatie geen volledige vrijheid mag worden gelaten; die bestaat zelfs niet, zoals wij later zullen zien, voor de leden van de maatschap en dus stellig niet in het geval van de medewerker. Die vrijheid is er uit den aard der zaak niet en kản zelfs niet bestaan, indien, zoals ook vaak voorkomt, de accountant persoonlijk de leiding behoudt. Dan rijst echter geen bijzondere moeilijkheid. De functie en de verantwoordelijkheid worden niet integraal overgedra- 
gen; de medewerker, ofschoon bevoegd om de verantwoordelijkheid te dragen, ziet deze toch niet aan zich gedelegeerd. In alle gevallen rijst de vraag, hoe gehandeld moet worden in geval van verschillend inzicht, een vraag, die het meest epineus is in de eerste gevallen.

Is er een blijvend meningsverschil t.a.v. de methode van werken, rapporteren enz., dan is de medewerker gehouden te vertrekken, onverschillig of hij geheel zelfstandig optreedt of niet. Op den duur zal hij zeker zich niet kunnen veront schuldigen voor tekortkomingen in de functie die hij heeft vervuld, met een be roep op de verhouding tussen werkgever en werknemer.

Het bijzondere geval behoeft niet tot deze consequentie te leiden. (Behoudens het geval van kwade trouw natuurlijk.) Het zal hier van de absolute betekenis van het geval afhangen, of de medewerker zich zal hebben te voegen naar het inzicht van de accountant of niet. Zo neen, dan bestaat de mogelijkheid van de ontslag. neming, maar ook de mogelijkheid van de uitdrukkelijke weigering tot medewer king in dit geval c.q. teruggeving van de delegatie der verantwoordelijkheid, in dien de werkgever zijn wil oplegt voor een controle die uitloopt in een door de medewerker te ondertekenen verklaring.

DE VERANTWOORDELIJKHEID VAN DE LEDEN VAN DE MAATSCHAP VOOR DE ARBEID VAN DE MEDEVENNOTEN

Vooropgesteld zij dat de leden van een maatschap verantwoordelijkheid hebben met betrekking tot elkanders arbeid. De omstandigheid, dat men met elkaar als accountants aan het maatschappelijk verkeer deelneemt, brengt die verantwoor. delijkheid onvermijdbaar mee. Hoe ook de juridische en economische verhoudin gen tussen de leden van de maatschap mogen zijn geregeld, het gezamenlijk op treden in het verkeer wekt het vertrouwen van een gezamenlijke arbeid en daar uit volgt logisch de gezamenlijke verantwoordelijkheid."

In het eerste deel van dit artikel werd reeds ingegaan in algemene zin op de ver. antwoordelijkheid en de relatie met de moraal. Het fungeren van een dienst bij de overheid schept dezelfde institutionele verantwoordelijkheid als die van een particulier accountantskantoor. Geconcludeerd kan dan ook worden dat de vak technische organisatie binnen de diensten van dezelfde beginselen dient uit te gaan als die voor public-accountants geldt. Het niet regelen van deze organisatie in het discussie-rapport is mogelijk een gevolg van het ontbreken van macht op het terrein van de interne aangelegenheden der diensten. Maar hiermede is het essentiële element onopgelost gebleven. De moraal is ook van grote betekenis voor de verdeling van macht en verantwoordelijkheid over personen en organisaties.

\section{ad b. DE ONAFHANKELUJKHEID}

Direct hiermede verbonden is de problematiek van de onafhankelijkheid in wezen. De autocratische structuur van de accountants diensten heeft tot gevolg dat er een onderscheid moet worden gemaakt tussen de hoofden en de medewer. kers-accountants. In sommige diensten is de concentratie van de zeggenschap al dus geregeld dat uitsluitend het hoofd van de dienst de verklaringen afgeeft en daarmee de structuur nog eens accentueert. Maar ook bij tekeningsbevoegdheid van de medewerkers is de structuur dusdanig opgezet dat het hoofd de zeggen 
schap behoudt. Van een democratische bestuursvorm is veelal geen sprake. De opbouw in rangen en de hiërarchische verhoudingen binnen de overheid hebben tot gevolg dat de macht zich concentreert bij de top.

Laten wij nu eens onderzoeken wat er terecht komt van de onafhankelijkheid in wezen. Hierbij dienen wij onderscheid te maken tussen het hoofd en de me. dewerkers. De concentratie van de verantwoordelijkheid bij het hoofd betekent reeds een geringe macht. Wanneer een democratische overlegstructuur binnen de dienst niet een goede machtsverdeling heeft gecreëerd betekent zulks een uitholling van de macht tegenover derden. Slechts samenwerking in democratische zin kan de onafhankelijkheid in wezen vergroten.

Voor de accountants-medewerkers zal de onafhankelijkheid in wezen mogelijk bij een democratisering kunnen toenemen. Veel hangt af van het persoonlijk karakter van het hoofd. Deze beslist namelijk over de promotie van zijn medewer. kers. Ook ten aanzien van dit punt is een collectieve besluitvorming de enige mo. gelijkheid de onafhankelijkheid te vergroten.

$\mathrm{Nu}$ hebben wij een interessante situatie. De medewerkers (volwaardige registeraccountants) zullen de democratische structuur wel ondersteunen. Het niet tot stand komen kan slechts andere oorzaken hebben. Enerzijds zijn de hoofden belanghebbenden, anderzijds de beheersorganen binnen de overheid. Zouden de hoofden de structuur niet wensen dan is dit een illustratie van de afhankelijkheid der medewerkers en een bevestiging van de gegeven analyses. Liggen de problemen bij de beheersorganen dan kan eveneens geconcludeerd worden dat de onafhankelijkheid slechts schijn is.

\section{v. Samenvatting}

De commissie heeft wel enige voorstellen gedaan die de onafhankelijkheid in schijn vergroten. Om de onafhankelijkheid in wezen te vergroten dienen de structuren binnen de accountantsdiensten gewijzigd te worden. Verantwoordelijkheid, macht, rechtsregels, onafhankelijkheid en moraal zijn hierbij relevant. 